\title{
Editorial
}

\section{Emergency Medicine in Sri Lanka}

Journal of the Ceylon College of Physicians, 2017, 48, 1

This volume has dedicated a substantial section to explore a relatively new field within our health care system - Emergency Medicine. We acknowledge with gratitude the contributions made herein by our Australian colleagues, have helped our own groups of personnel for over a decade. From igniting our local interest in the specialty to formal capacity building, from establishing a state of the art centre in Karapitiya with funding from the state of Victoria after the tsunami of 2004 to assist in the development of a dedicated postgraduate training course in the PGIM and in the conduct of formal assessments and examination for the $1^{\text {st }}$ batch of budding specialists in Emergency Medicine - the Sri Lanka Australian collaboration has indeed been very fruitful and fulfilling.

The field of Emergency Medicine encourages multiple spheres to work together as individuals and institutions. This Journal helps shed light on its definition and scope, includes the case mix to be expected in any standard facility in Sri Lanka. Although we appear to focus upon a relatively new concept within our local health system, many of us have flashbacks on how the concept of a facility called the ETU (emergency treatment unit), which is now ubiquitous, in fact became a reality. My memories of the mid 1980s recall how this came to light. Our then head of state experienced the unexpected loss of a young employee who succumbed to acute myocardial infarction when being wheeled into a distantly located medical ward after formal admission without emergency care by the outpatients department of NHSL. An inquiry into this sad outcome, that most probably could have been avoided, brought into action the concept of an on-site ETU.

We have made much progress since then. The Ministry of Health spearheaded the formal policy on Emergency Medicine and in parallel the PGIM formalized training from early part of this decade. Our College was a main stakeholder in the planning, with sustained encouragement by successive Councils. Numerous discussions and deliberations were required to formalize the process. Our sister colleges of Surgeons, Paediatricians, Obstetricians, Anaesthesiologists and Intensivists joined hands to develop strategic action plans, identify human and technical resource need, outline a pragmatic triage system, and formalize the postgraduate training to ensure essential leadership in centres that developed formal Emergency Care facilities at provincial and district level. This process has now been institutionalized and currently being rolled out island wide. Our own College members have helped immeasurably in this transition. Hence, the field of Emergency Medicine needs the due attention of all practicing physicians in Sri Lanka.

The emergence of Emergency Medicine as a dedicated specialty is nothing new in the world over. The USA and Canada led the way over 50 years ago. Revisiting the history of its emergence provides us, who can possibly be regarded as 'late responders', to the best rationale for establishing the field of Emergency Medicine in Sri Lanka. Our own College was quick to respond when the formal process was initiated. The CCP worked hand in hand with the Directorate for Quality and Safety of the Ministry of Health under the able leadership of the Deputy Director of Medical Services II. It is our bounden duty to ensure the optimal implementation of the field of Emergency Medicine within our own hospital facilities in collaboration across specialties. It is also our duty to ensure that relevant Emergency Medicine training is instituted in all our CPD programmes at central and regional level. Data gathering and audits must also be encouraged to measure our own quality of care linked to formal mortality-morbidity meetings conducted at institutional, regional and national level.

There has been much done and much more to be done.

\section{Chandrika N Wijeyaratne}

Co Editor

JCCP 